\title{
Low Prevalence of Clinically Significant Endoscopic Findings in Outpatients with Dyspepsia
}

\author{
Khaled Abdeljawad, ${ }^{1}$ Antonios Wehbeh, ${ }^{2}$ and Emad Qayed ${ }^{1}$ \\ ${ }^{1}$ Department of Medicine, Division of Digestive Diseases, Emory University School of Medicine, Atlanta, GA, USA \\ ${ }^{2}$ Department of Medicine, Emory University School of Medicine, Atlanta, GA, USA \\ Correspondence should be addressed to Emad Qayed; eqayed@emory.edu
}

Received 31 July 2016; Revised 20 November 2016; Accepted 18 December 2016; Published 22 January 2017

Academic Editor: Qasim Aziz

Copyright (c) 2017 Khaled Abdeljawad et al. This is an open access article distributed under the Creative Commons Attribution License, which permits unrestricted use, distribution, and reproduction in any medium, provided the original work is properly cited.

Background. The value of endoscopy in dyspeptic patients is questionable. Aims. To examine the prevalence of significant endoscopic findings (SEFs) and the utility of alarm features and age in predicting SEFs in outpatients with dyspepsia. Methods. A retrospective analysis of outpatient adults who had endoscopy for dyspepsia. Demographic variables, alarm features, and endoscopic findings were recorded. We defined SEFs as peptic ulcer disease, erosive esophagitis, malignancy, stricture, or findings requiring specific therapy. Results. Of 650 patients included in the analysis, $51 \%$ had a normal endoscopy. The most common endoscopic abnormality was nonerosive gastritis (29.7\%) followed by nonerosive duodenitis (7.2\%) and LA-class A esophagitis (5.4\%). Only 10.2\% had a SEF. Five patients (0.8\%) had malignancy. SEFs were more likely present in patients with alarm features (12.6\% versus $5.4 \%, p=0.004)$. Age $\geq 55$ and presence of any alarm feature were associated with SEFs (aOR 1.8 and 2.3, resp.). Conclusion. Dyspeptic patients have low prevalence of SEF. The presence of any alarm feature and age $\geq 55$ are associated with higher risk of SEF. Endoscopy in young patients with no alarm features has a low yield; these patients can be considered for nonendoscopic approach for diagnosis and management.

\section{Introduction}

Dyspepsia is defined as chronic or recurrent pain or discomfort centered in the upper abdomen [1]. It involves a variety of symptoms such as epigastric pain or burning, early satiety, bloating, upper abdominal fullness, or nausea $[2,3]$. Functional dyspepsia is defined by the Rome IV consensus as the presence of one or more of the following: bothersome postprandial fullness, bothersome early satiation, or bothersome epigastric pain or burning, with no evidence of structural disease to explain the symptoms. The criteria should be fulfilled for the last three months with symptom onset at least six months before diagnosis [4]. Dyspepsia is one of the most commonly encountered gastrointestinal complaints in the outpatient and inpatient settings. It is estimated that around $25-35 \%$ of the US population are affected by dyspepsia $[3,5,6]$. Dyspepsia has huge economic costs to patients and to the healthcare system. Patients with dyspepsia have lower work productivity and more sick leaves [7-10].
The approach for evaluating and managing patients with dyspepsia focuses on identifying high risk patients including those older than 55 years and those with one or more alarm features (bleeding, anemia, early satiety, unexplained weight loss, dysphagia, odynophagia, vomiting, family history of gastrointestinal cancer, previous esophagogastric malignancy, previous documented peptic ulcer, previous upper gastrointestinal surgery, lymphadenopathy, or an abdominal mass). It is recommended that these two groups of patients undergo Esophagogastroduodenoscopy (EGD) to exclude an organic pathology such as esophagogastric malignancy and peptic ulcer disease. Otherwise, patients can be managed by either the "test and treat" strategy for $H$. pylori or a trial of proton pump inhibitor (PPI) depending on the $H$. pylori prevalence $[1,11]$. The yield of endoscopy in patients with dyspepsia is questionable and varies among studies; part of this variation is due to different definitions of dyspepsia used by different studies $[6,12]$. A systematic review by Ford et al. examined studies that reported prevalence of endoscopic findings in 
outpatients with dyspepsia. A clinically significant finding was defined as erosive esophagitis, Barrett's esophagus, gastric or duodenal ulcer disease, and gastroesophageal malignancy. The pooled prevalence of significant endoscopic findings was $27.5 \%$ when using a broad definition of dyspepsia or $18 \%$ when including studies using the Rome criteria to define dyspepsia [13]. The most common clinically significant finding encountered was erosive esophagitis (20\%) when using broad definition of dyspepsia or peptic ulcer disease (11\%) when using the Rome criteria to define dyspepsia. Most of the included studies used a questionnaire to screen for eligible patients instead of medical staff evaluation, and in some studies all patients underwent endoscopy regardless of symptoms, age, or presence of alarm features [12, 1418]. One study only included patients with positive H. pylori infection [19]. Those factors could have led to a higher prevalence of significant endoscopic findings. The utility of alarm features and age cutoff of 55 years in predicting the presence of significant endoscopic findings is unknown [2022]. Furthermore, a large proportion of low risk patients with dyspepsia defined as younger than 55 and with no alarm features do not receive a trial of PPI or $H$. pylori testing prior to endoscopy [23]. In addition, it seems that many primary care physicians and even gastroenterologists do not define dyspepsia correctly and do not adhere to dyspepsia guidelines [24]. Due to the high prevalence of dyspepsia, a prompt endoscopy for every dyspeptic patient is not a practical approach, as this will lead to high costs and low yield of endoscopy [12, 25-27].

This study provides further clarification on the prevalence of significant endoscopic findings in outpatients with dyspepsia. It also evaluates the role of age and alarm features in clinical decision making regarding which patients should be referred to endoscopy. The primary aim of this study is to investigate whether age $\geq 55$ and/or presence of any alarm feature predicts the presence of significant endoscopic findings (SEFs) in outpatients with dyspepsia at a large teaching hospital.

\section{Methods}

This is a retrospective study using the endoscopic procedure database at Grady Memorial Hospital in Atlanta, Georgia. This database prospectively collects information about all endoscopic procedures performed at the Gastroenterology unit, including procedure type, patient's medical record number, age, race, sex, procedure, indications, and findings. The study was approved by the Institutional Review Board. Inclusion criteria included all upper endoscopies performed in the outpatient setting for patients who were at least 18 year old and referred for dyspepsia between June 1, 2011, and July 1, 2015. Endoscopy referrals for patients with upper GI symptoms are made through the GI clinic, emergency department, primary care, and subspecialty physician offices. In our practice, most patients are seen in the GI clinic before their endoscopy. There are no specific referral criteria to the GI clinic. The decision to refer patients from the GI clinic to undergo upper endoscopy is at the discretion of the clinic physicians, based on age, severity of symptoms, and response to prior treatment. The medical record was carefully reviewed and the presence of dyspepsia symptoms (nausea, vomiting, epigastric pain/discomfort, postprandial fullness, belching, and early satiation) was recorded. Patients with heartburn and/or regurgitation were included only if they had accompanying dyspeptic symptoms. The medical record was also used to confirm endoscopic findings and collect further information about patients such as alcohol consumption, smoking status, and pertinent medications such as NSAIDs, PPI, H2-blockers, anticoagulants, ASA, and other antiplatelets. H. pylori infection status prior to endoscopy was recorded. At our institution, this is tested with the stool antigen test or serum antibody. Alarm features were recorded: (vomiting, weight loss, dysphagia, odynophagia, bleeding, anemia, early satiety, personal or family history of upper GI cancers, history of peptic ulcer disease, lymph node enlargement, or abdominal mass). Endoscopic findings were recorded in detail. We defined significant endoscopic findings as the presence of any of the following findings: gastric ulcer, duodenal ulcer, erosive esophagitis (LA grade B and higher), malignancy, stricture, or other findings that required specific therapy and were judged to have contributed to the patient's symptoms.

2.1. Statistical Analysis. Descriptive statistics were used to characterize patient demographic features. Continuous variables were summarized using mean and standard deviation, and categorical variables were summarized using number and percentage. We also categorized age as $\geq 55$ and $<55$ years. We compared the presence of endoscopic findings in patients with and without alarm features and in patients within different age categories. The Chi-square test of independence was performed to examine the association of different endoscopic findings with the presence of alarm features. To examine the combined effect of age and presence of any alarm features on the presence of significant endoscopic findings, multivariate logistic regression was performed to examine the association of different factors (presence of any alarm feature, age $\geq 55$, smoking, race, gender, PPI use, H. pylori status, NSAIDs, and alcohol) with the presence of significant endoscopic findings. Backward elimination was performed to remove nonsignificant covariates with a $p$ value of $>0.05$.

\section{Results}

During the study period, 16,020 endoscopic procedures were performed, of which there were 4501 EGDs. Of those, 650 were performed for outpatients with dyspeptic symptoms and were included in the analysis. Table 1 shows the basic demographics of the study population. The average age was 48.4 years \pm 12.6 . Two-thirds of the patients were younger than 55 years; 473 (72.8\%) were females; 423 (65.1\%) were African Americans; 161 (24.8\%) patients were smokers and $65(9.5 \%)$ used alcohol heavily. Among all patients, 504 (77.5\%) were using Nonsteroidal Anti-Inflammatory Drugs (NSAIDs) at the time of the procedure or preendoscopic clinic visit, and $456(70.2 \%)$ patients were on a PPI. Aspirin was used by 114 (17.5\%) patients. H. pylori status was unknown in $350(53.8 \%)$ of the patients, positive and treated prior to 
TABLE 1: Basics characteristics of outpatients with dyspepsia; Grady Memorial Hospital, Atlanta, Georgia, June 1, 2011-July 1, 2015.

\begin{tabular}{|c|c|c|}
\hline Characteristic & $n(650)$ & $\%$ \\
\hline \multicolumn{3}{|l|}{ Age } \\
\hline$<55$ years & 433 & 66.6 \\
\hline$\geq 55$ years & 217 & 33.4 \\
\hline \multicolumn{3}{|l|}{ Gender } \\
\hline Female & 473 & 72.8 \\
\hline Male & 177 & 27.3 \\
\hline \multicolumn{3}{|l|}{ Race } \\
\hline Black & 423 & 65.1 \\
\hline Hispanic & 112 & 17.2 \\
\hline White & 57 & 8.8 \\
\hline Other & 58 & 8.9 \\
\hline Smoking & 161 & 24.8 \\
\hline \multicolumn{3}{|l|}{ Alcohol use } \\
\hline None & 456 & 70.2 \\
\hline Occasional & 132 & 20.3 \\
\hline Heavy & 62 & 9.5 \\
\hline \multicolumn{3}{|l|}{ Medications } \\
\hline NSAIDs & 504 & 77.5 \\
\hline PPI & 456 & 70.2 \\
\hline H2-blocker & 138 & 21.2 \\
\hline ASA & 114 & 17.5 \\
\hline Other antiplatelets & 7 & 1.1 \\
\hline Anticoagulant & 5 & 0.8 \\
\hline \multicolumn{3}{|l|}{ H. pylori status prior to EGD } \\
\hline Unknown & 350 & 53.8 \\
\hline Positive and treated & 140 & 21.5 \\
\hline Negative & 126 & 19.4 \\
\hline Positive and not treated & 34 & 5.2 \\
\hline \multicolumn{3}{|l|}{ Dyspepsia symptoms } \\
\hline Epigastric pain & 498 & 76.6 \\
\hline Nausea & 280 & 43.1 \\
\hline Vomiting & 170 & 26.2 \\
\hline Epigastric burning & 138 & 21.2 \\
\hline Early satiety & 79 & 12.2 \\
\hline Belching & 34 & 5.2 \\
\hline \multicolumn{3}{|l|}{ Reflux symptoms } \\
\hline Heartburns & 172 & 26.5 \\
\hline Regurgitation & 43 & 6.6 \\
\hline \multicolumn{3}{|l|}{ Alarm feature } \\
\hline Vomiting & 170 & 26.2 \\
\hline Weight loss & 138 & 21.2 \\
\hline Anemia & 103 & 15.8 \\
\hline Early satiety & 79 & 12.2 \\
\hline Dysphagia & 76 & 11.7 \\
\hline Previous peptic ulcer disease & 41 & 6.3 \\
\hline Bleeding & 38 & 5.8 \\
\hline Family history of GI cancer & 29 & 4.5 \\
\hline Prior upper GI surgery & 28 & 4.3 \\
\hline Previous GI cancer & 12 & 1.8 \\
\hline Odynophagia & 8 & 1.2 \\
\hline Lymphadenopathy or abdominal mass & 4 & 0.6 \\
\hline
\end{tabular}

NSAIDs: Nonsteroidal Anti-Inflammatory Drugs; PPI: proton pump inhibitor; ASA: aspirin; EGD: Esophagogastroduodenoscopy; GI: gastrointestinal.

endoscopy in 140 (21.5\%) patients, negative in 126 (19.4\%) patients, and positive and untreated prior to endoscopy in 34 (5.2\%) of patients.
The most encountered dyspepsia symptom was epigastric pain $(76.6 \%)$, followed by nausea $(43.1 \%)$ and vomiting (26.2\%). Among all patients, $65.7 \%$ had one or more alarm features. Vomiting was the most common alarm feature (26.2\%), followed by weight loss (21.2\%) and anemia (15.8\%). Of note, 28 (4.3\%) patients had prior upper GI surgery, such as Billroth I and II and Nissen fundoplication. There were no reported major complications or deaths related to endoscopy during the study period.

3.1. Endoscopic Findings. Table 2 shows the findings of endoscopy stratified by the presence or absence of alarm features. Among all patients, 321 (49.4\%) had any endoscopic abnormality. This did not statistically differ between patients with alarm features versus no alarm features (48.7\% versus $50.7 \%$, resp., $p=0.63)$. Only $66(10.2 \%)$ patients had significant endoscopic findings. This was more likely to be found in patients with alarm features compared to those without any alarm features (12.6\% versus 5.4\%, $p=0.004)$. The most common endoscopic abnormality was nonerosive gastritis $(29.7 \%)$, followed by nonerosive duodenitis $(7.2 \%)$ and Los Angeles class A esophagitis (5.4\%). Peptic ulcer disease was found in $26(4 \%)$ of patients. This was more likely to be found in patients with alarm features compared to those without any alarm features $(5.4 \%$ versus $1.3 \%, p=$ $0.01)$. Malignancy was found in only $5(0.8 \%)$ patients, all of whom had one or more alarm features. Two patients had gastric adenocarcinoma, one had GIST tumor, one had MALT lymphoma, and one had squamous cell carcinoma of the esophagus.

Other SEFs were found in $25(3.8 \%)$ patients. There were no significant differences in the presence of other SEFs between patients with and without alarm features $(4.7 \%$ versus $2.2 \%$, resp., $p=0.12$ ). Other nonsignificant endoscopic findings (benign polyps and nonobstructive Schatzki's ring) were found in $6 \%$ of patients, and they were similar in distribution between patients with and without alarm features $(6.7 \%$ versus $5.2 \%$, resp., $p=0.41)$.

3.2. Significant Endoscopic Findings according to Age. SEFs in patients with and without alarm features as stratified by age are shown in Table 3. Older patients had a higher likelihood of having significant endoscopic findings. The prevalence of endoscopic abnormalities in patients without alarm features younger than 55 years was low (7/156, 4.5\%), with the lowest prevalence in those younger than 40 years $(1 / 64,1.6 \%)$. The presence or absence of alarm features was predictive of SEFs among the main age categories $(<55, \geq 55)$.

Multivariable logistic regression analysis showed that age $\geq 55$, presence of any alarm feature, and smoking were significantly associated with the presence of SEFs (Table 4). Having more than one of these risk factors significantly increases the chance of SEFs. Race, gender, PPI use prior to endoscopy, H. pylori status, NSAIDs, and alcohol use were not associated with SEFs. 
TABLE 2: Endoscopic findings in outpatients with dyspepsia, stratified by alarm features; Grady Memorial Hospital, Atlanta, Georgia, June 1, 2011-July 1, 2015.

\begin{tabular}{|c|c|c|c|c|c|c|c|}
\hline \multirow{2}{*}{ Characteristic } & \multicolumn{2}{|c|}{ All patients } & \multicolumn{2}{|c|}{ No alarm features } & \multicolumn{2}{|c|}{ Any alarm feature } & \multirow{2}{*}{$p$ value } \\
\hline & $n(650)$ & $\%$ & $n(223)$ & $34.3 \%$ & $n(427)$ & $65.7 \%$ & \\
\hline Any endoscopic abnormality & 321 & 49.4 & 113 & 50.7 & 208 & 48.7 & 0.63 \\
\hline Significant endoscopic abnormality & 66 & 10.2 & 12 & 5.4 & 54 & 12.6 & 0.004 \\
\hline Any peptic ulcer disease & 26 & 4 & 3 & 1.3 & 23 & 5.4 & 0.01 \\
\hline Gastric & 17 & 2.6 & 3 & 1.3 & 14 & 3.3 & 0.14 \\
\hline Duodenal & 11 & 1.7 & 0 & 0 & 11 & 2.6 & 0.02 \\
\hline \multicolumn{8}{|l|}{ Gastritis } \\
\hline Erosive & 43 & 6.6 & 15 & 6.7 & 28 & 6.6 & 0.93 \\
\hline Nonerosive & 193 & 29.7 & 74 & 33.2 & 119 & 27.9 & 0.16 \\
\hline \multicolumn{8}{|l|}{ Duodenitis } \\
\hline Erosive & 5 & 0.8 & 1 & 0.4 & 4 & 0.9 & 0.5 \\
\hline Nonerosive & 47 & 7.2 & 14 & 6.3 & 33 & 7.7 & 0.54 \\
\hline Malignancy & 5 & 0.8 & 0 & 0 & 5 & 1.2 & 0.1 \\
\hline \multicolumn{8}{|l|}{ Esophagitis } \\
\hline Los Angeles class A & 35 & 5.4 & 11 & 4.9 & 24 & 5.6 & 0.71 \\
\hline Los Angeles classes B, C, and D & 16 & 2.5 & 5 & 2.2 & 11 & 2.6 & 0.79 \\
\hline Other significant endoscopic findings & 25 & 3.8 & 5 & 2.2 & 20 & 4.7 & 0.12 \\
\hline Anastomotic stricture & 4 & & 0 & & 4 & & \\
\hline Candida esophagitis & 4 & & 0 & & 4 & & \\
\hline Anastomotic ulcer & 3 & & 0 & & 3 & & \\
\hline Severe hemorrhagic gastritis & 3 & & 2 & & 1 & & \\
\hline Barrett's esophagus & 3 & & 1 & & 2 & & \\
\hline Esophageal benign stricture & 2 & & 0 & & 2 & & \\
\hline Esophageal varices & 2 & & 1 & & 1 & & \\
\hline Extrinsic compression & 1 & & 0 & & 1 & & \\
\hline Gastric bezoar & 1 & & 0 & & 1 & & \\
\hline Paraesophageal hernia & 1 & & 1 & & 0 & & \\
\hline Fobi-ring erosion & 1 & & 0 & & 1 & & \\
\hline Other nonsignificant endoscopic findings & 37 & 6 & 15 & 6.7 & 22 & 5.2 & 0.41 \\
\hline Benign polyps & 31 & & 12 & & 19 & & \\
\hline Nonobstructive Schatzki’s ring & 6 & & 3 & & 3 & & \\
\hline
\end{tabular}

LA: Los Angeles.

\section{Discussion}

In this study, we found a low prevalence of significant endoscopic findings $(10.2 \%)$ in outpatients with dyspepsia, and the majority of these were found in patients with alarm features. The prevalence of malignancy was extremely low (5 cases, $0.8 \%$ ), and all 5 cases were present in patients with alarm features. This highlights the low yield of endoscopy in patients with dyspepsia and calls for a more conservative, nonendoscopic approach in management. This is especially true in patients without alarm features and younger than 55 years, where the prevalence of SEFs was $4.5 \%$. While this could arguably be considered a significant percentage, none of these patients had malignancy. It is unlikely that treatment would significantly change in this small group of patients if they had undergone endoscopy, given that PPI and H. pylori testing are the mainstay of treatment. This study confirms the role of alarm features and age $\geq 55$ in predicting the presence of SEFs. Patients with alarm features were more likely to have SEF compared to those with no alarm features (12.7 versus $5.4 \%, p=0.004)$. Patients with both alarm features and age $\geq 55$ had a $17 \%$ chance of having SEFs. Alarm feature and age $\geq 55$ remained significant predictors of SEFs in multivariate analysis. In addition, we found that smoking is as useful in predicting SEFs as age $\geq 55$ (aOR of 1.8 for both risk factors). Previous studies showed that smoking could increase the risk of peptic ulcerations [28-31]. Therefore, smoking could be considered an independent alarm feature and an important element in clinical decision making when stratifying patients with dyspepsia to undergo endoscopy. As expected, we found that combining several risk factors increased the chance of SEFs. For example, patients $\geq 55$ years with any alarm feature had 4.2 (CI: 1.8-9.5) higher odds of having SEFs when compared to patients who were $<55$ years without alarm features (aOR 4.2).

In our study, we included patients with prior upper GI surgeries who are at risk of anastomotic complications such 
TABle 3: Significant endoscopic findings in patients with and without alarm features stratified by age; Grady Memorial Hospital, Atlanta, Georgia, June 1, 2011-July 1, 2015.

\begin{tabular}{lccc}
\hline Age & No alarm features & With any alarm feature & $p$ value \\
\hline$<55$ & $7 / 156(4.5 \%)$ & $28 / 277(10.1 \%)$ & 0.04 \\
$<40$ & $1 / 64(1.6 \%)$ & $8 / 104(7.7 \%)$ & NS \\
$40-54$ & $6 / 92(6.5 \%)$ & $20 / 173(11.6 \%)$ & NS \\
$\geq 55$ & $5 / 67(7.5 \%)$ & $26 / 150(17.3 \%)$ & 0.045 \\
Total & $12 / 223(5.4 \%)$ & $54 / 427(12.6 \%)$ & 0.004 \\
\hline
\end{tabular}

NS: not significant.

TABLE 4: Multivariate analysis of association of risk factors with significant endoscopic findings; Grady Memorial Hospital, Atlanta, Georgia, June 1, 2011-July 1, 2015.

\begin{tabular}{lcc}
\hline Risk factor(s) & aOR (95\% CI) & $p$ value \\
\hline Any alarm feature & $2.3(1.2-4.4)$ & 0.01 \\
Age $\geq 55$ & $1.8(1.1-3)$ & 0.02 \\
Smoking & $1.8(1.1-3.1)$ & 0.03 \\
Any alarm feature and age $\geq 55$ & $4.2(1.8-9.5)$ & 0.0007 \\
Any alarm feature and smoking & $4.1(1.8-9.4)$ & 0.0005 \\
Any alarm feature, age $\geq 55$, and smoking & $7.5(2.9-19)$ & $<0.0001$ \\
\hline
\end{tabular}

aOR: adjusted odds ratio. Final model included any alarm feature, age $\geq 55$, and smoking. Race, gender, PPI use prior to endoscopy, H. pylori status, NSAIDs, and alcohol use had a nonsignificant association with endoscopic findings and were removed from the final model.

as marginal ulcers and anastomotic strictures [32-35]. Prior GI surgery was considered an alarm feature. Of 28 patients with prior upper GI surgery, 9 (32\%) had significant findings (four anastomotic strictures, 3 anastomotic ulcers, one Fobiring erosion, and one candida esophagitis). This group of patients is at high risk of complications and endoscopy is always warranted to investigate upper GI symptoms.

Despite the low yield of endoscopy in outpatients with dyspepsia, a negative endoscopy can improve patient satisfaction and relieve anxiety due to fear of serious illnesses $[36,37]$. In our study, the most common SEF was peptic ulcer disease $(4 \%)$. We found lower prevalence of erosive esophagitis due to including patients with GERD only if they had accompanying dyspepsia symptoms. Our study found a low prevalence of malignancy in patients with dyspepsia $(0.8 \%)$ which is comparable to previous studies $(<0.5 \%)$ [13]. The study revealed a relatively lower prevalence of SEFs compared to other studies due to multiple factors. Previous studies were statistically heterogeneous [12, 14-19, 38]. Patients in our study were evaluated in the outpatient settings, given an appointment for their endoscopy, which usually takes several weeks to complete. In the meanwhile, they might be given a trial of PPI or asked to discontinue possible culprit medications, such as NSAIDs. This could have allowed the healing of some lesions and prevented their detection at the time of endoscopy. However, this is reflective of daily practice and should not be considered a weakness in this study.

Our study has several limitations. It had a retrospective design, was performed in a single center, and lacked cost analysis. In a randomized clinical trial, Laheij et al. randomized patients with dyspepsia referred to endoscopy to either prompt endoscopy followed by directed medical treatment versus empirical treatment with PPI followed by testing and treating $H$. pylori in the case of relapse [30]. They found that the empirical drug treatment resulted in less diagnostic endoscopies, lower costs, and equal effectiveness in the first year of follow-up. We did not collect data on celiac disease serologies in our patients because we do not routinely screen patients with dyspepsia for celiac disease in our practice. The prevalence of celiac disease in patients with dyspepsia varies between 0.5 and $2 \%$ [39]. This is expected to be much lower in our hospital where the majority of patients are African Americans (65\%). Therefore, we do not think there were missed cases of celiac disease in our patient population.

Our study has several strengths. Despite our retrospective design, we were able to extract all information about patient demographics, symptoms and signs, and endoscopic findings from the medical record. Furthermore, we attempted to examine the utility of endoscopy in patients with dyspepsia in a more pragmatic setting rather than a randomized clinical trial. We did not find prior treatment with PPI or H. pylori status to be predictive of endoscopic findings, probably due to the low prevalence of peptic ulcer disease (4\%). We also focused our study on outpatients with dyspepsia, as inpatients tend to have more severe symptoms and comorbidities, and therefore the approach to their management should be separate from outpatients. Finally, we chose to define "significant endoscopic findings" as one composite outcome that includes findings pertinent to the patients' management and related to their symptoms. We did not consider simple erosive or nonerosive gastroduodenal inflammation as a significant finding given that it is unlikely to contribute to the patients' symptoms or alter their long-term management. Previous studies showed poor association of these findings with dyspeptic symptoms [40, 41]. Erosive esophagitis class $\mathrm{B}$ and higher was considered significant, as it would require long-term maintenance treatment with PPI.

In summary, the prevalence of significant endoscopic findings in outpatients with dyspepsia is low, particularly in patients younger than 55 years and without alarm features. Guidelines should highlight the low yield of endoscopy in this group of patients and recommend nonendoscopic workup or empiric therapy as alternatives to endoscopy. Those patients should also be reassured that their symptoms are unlikely related to an underlying significant pathology and should be encouraged to defer endoscopy. The presence of any alarm feature, age $\geq 55$, and smoking are all independent predictors of significant endoscopic findings. An approach to outpatients with dyspepsia that considers an age cutoff $\geq 55$ and presence of any alarm features as indications for endoscopy is a simple and straightforward management strategy. However, a scoring system that considers multiple additional risk factors (such as smoking) is likely to improve the yield of endoscopy in dyspepsia and allow for a more accurate stratification of patients to endoscopic workup versus nonendoscopic workup or empiric therapy. Further studies are required to clarify the role of each alarm feature in predicting significant endoscopic findings and compile a 
more concise list of predictive risk factors to be used as a scoring system that guides clinical decision making.

$\begin{array}{ll}\text { Abbreviations } \\ \text { SEF: } & \text { Significant endoscopic findings } \\ \text { GERD: } & \text { Gastroesophageal reflux disease } \\ \text { H. pylori: } & \text { Helicobacter pylori } \\ \text { PPI: } & \text { Proton pump inhibitor } \\ \text { EGD: } & \text { Esophagogastroduodenoscopy } \\ \text { NSAIDs: } & \text { Nonsteroidal Anti-Inflammatory Drugs } \\ \text { ASA: } & \text { Aspirin } \\ \text { GI: } & \text { Gastrointestinal } \\ \text { LA: } & \text { Los Angeles } \\ \text { GIST: } & \text { Gastrointestinal stromal tumors } \\ \text { MALT: } & \text { Mucosa associated lymphoid tissue } \\ \text { CI: } & \text { Confidence interval } \\ \text { aOR: } & \text { Adjusted odds ratio. }\end{array}$

\section{Competing Interests}

The authors have no conflict of interests to declare.

\section{References}

[1] N. J. Talley and N. Vakil, "Guidelines for the management of dyspepsia," American Journal of Gastroenterology, vol. 100, no. 10, pp. 2324-2337, 2005.

[2] J. Tack and N. J. Talley, "Functional dyspepsia-symptoms, definitions and validity of the Rome III criteria," Nature Reviews Gastroenterology and Hepatology, vol. 10, no. 3, pp. 134-141, 2013.

[3] J. Tack, N. J. Talley, M. Camilleri et al., "Functional Gastroduodenal Disorders," Gastroenterology, vol. 130, no. 5, pp. 14661479, 2006.

[4] D. A. Drossman and W. L. Hasler, "Rome IV_functional GI disorders: disorders of gut-brain interaction," Gastroenterology, vol. 150, no. 6, pp. 1257-1261, 2016.

[5] E. Castillo, M. CamillerI, G. Locke III et al., "A communitybased, controlled study of the epidemiology and pathophysiology of dyspepsia," Clinical Gastroenterology and Hepatology, vol. 2, no. 11, pp. 985-996, 2004.

[6] A. C. Ford, A. Marwaha, R. Sood, and P. Moayyedi, "Global prevalence of, and risk factors for, uninvestigated dyspepsia: a meta-analysis," Gut, vol. 64, no. 7, pp. 1049-1057, 2015.

[7] L. Agréus and L. Borgquist, "The cost of gastro-oesophageal reflux disease, dyspepsia and peptic ulcer disease in Sweden," PharmacoEconomics, vol. 20, no. 5, pp. 347-355, 2002.

[8] R. A. Brook, N. L. Kleinman, R. S. Choung, A. K. Melkonian, J. E. Smeeding, and N. J. Talley, "Functional dyspepsia impacts absenteeism and direct and indirect costs," Clinical Gastroenterology and Hepatology, vol. 8, no. 6, pp. 498-503, 2010.

[9] O. Nyren, H. O. Adami, S. Gustavsson, L. Lööf, and A. Nyberg, "Social and economic effects of non-ulcer dyspepsia," Scandinavian Journal of Gastroenterology. Supplement, vol. 109, pp. 41-47, 1985.

[10] G. B. Sander, L. E. Mazzoleni, C. F. D. M. Francesconi et al., "Influence of organic and functional dyspepsia on work productivity: the HEROES-DIP study," Value in Health, vol. 14, no. 5, pp. S126-S129, 2011.
[11] A. Shaukat, A. Wang, R. D. Acosta et al., "The role of endoscopy in dyspepsia," Gastrointestinal Endoscopy, vol. 82, no. 2, pp. 227232, 2015

[12] R. M. Zagari, G. R. Law, L. Fuccio, P. Pozzato, D. Forman, and F. Bazzoli, "Dyspeptic symptoms and endoscopic findings in the community: the loiano-monghidoro study," American Journal of Gastroenterology, vol. 105, no. 3, pp. 565-571, 2010.

[13] A. C. Ford, A. Marwaha, A. Lim, and P. Moayyedi, "What is the prevalence of clinically significant endoscopic findings in subjects with dyspepsia? Systematic review and meta-analysis," Clinical Gastroenterology and Hepatology, vol. 8, no. 10, pp. 830.e2-837.e2, 2010.

[14] P. Aro, J. Ronkainen, T. Storskrubb et al., "Valid symptom reporting at upper endoscopy in a random sample of the Swedish adult general population: the Kalixanda study," Scandinavian Journal of Gastroenterology, vol. 39, no. 12, pp. 1280-1288, 2004.

[15] B. Bernersen, R. Johnsen, B. Straume, P. G. Burhol, T. G. Jenssen, and P. A. Stakkevold, "Towards a true prevalence of peptic ulcer: The Sorreisa Gastrointestinal Disorder Study," Gut, vol. 31, no. 9, pp. 989-992, 1990.

[16] P. H. Katelaris, G. H. K. Tippett, P. Norbu, D. G. Lowe, R. Brennan, and M. J. G. Farthing, "Dyspepsia, Helicobacter pylori, and peptic ulcer in a randomly selected population in India," Gut, vol. 33, no. 11, pp. 1462-1466, 1992.

[17] C.-L. Lu, H.-C. Lang, F.-Y. Chang et al., "Prevalence and health/social impacts of functional dyspepsia in Taiwan: A study based on the Rome Criteria Questionnaire Survey Assisted by Endoscopic Exclusion Among A Physical Check-up Population," Scandinavian Journal of Gastroenterology, vol. 40, no. 4, pp. 402-411, 2005.

[18] Y. Shaib and H. B. El-Serag, "The prevalence and risk factors of functional dyspepsia in a multiethnic population in the United States," American Journal of Gastroenterology, vol. 99, no. 11, pp. 2210-2216, 2004.

[19] T. Azuma, Y. Ito, H. Suto et al., "The effect of Helicobacter pylori eradication therapy on dyspepsia symptoms in industrial workers in Japan," Alimentary Pharmacology and Therapeutics, vol. 15, no. 6, pp. 805-811, 2001.

[20] G. A. J. Fransen, M. J. R. Janssen, J. W. M. Muris, R. J. F. Laheij, and J. B. M. J. Jansen, "Meta-analysis: the diagnostic value of alarm symptoms for upper gastrointestinal malignancy," Alimentary Pharmacology and Therapeutics, vol. 20, no. 10, pp. 1045-1052, 2004.

[21] P. Moayyedi, N. J. Talley, M. B. Fennerty, and N. Vakil, "Can the clinical history distinguish between organic and functional dyspepsia?" Journal of the American Medical Association, vol. 295, no. 13, pp. 1566-1576, 2006.

[22] N. Vakil, P. Moayyedi, M. B. Fennerty, and N. J. Talley, “Limited value of alarm features in the diagnosis of upper gastrointestinal malignancy: systematic review and meta-analysis," Gastroenterology, vol. 131, no. 2, pp. 390-401, 2006.

[23] J. P. Fiorenza, A. M. Tinianow, and W. W. Chan, "The initial management and endoscopic outcomes of dyspepsia in a lowrisk patient population," Digestive Diseases and Sciences, vol. 61, no. 10, pp. 2942-2948, 2016.

[24] B. M. R. Spiegel, M. Farid, M. G. H. Van Oijen, L. Laine, C. W. Howden, and E. Esrailian, "Adherence to best practice guidelines in dyspepsia: a survey comparing dyspepsia experts, community gastroenterologists and primary-care providers," Alimentary Pharmacology and Therapeutics, vol. 29, no. 8, pp. 871-881, 2009. 
[25] W. D. Chey and P. Moayyedi, "Review article: uninvestigated dyspepsia and non-ulcer dyspepsia-the use of endoscopy and the roles of Helicobacter pylori eradication and antisecretory therapy," Alimentary Pharmacology \& Therapeutics, vol. 19, supplement 1, pp. 1-8, 2004.

[26] H. B. El-Serag and N. J. Talley, "Systematic review: the prevalence and clinical course of functional dyspepsia," Alimentary Pharmacology and Therapeutics, vol. 19, no. 6, pp. 643-654, 2004.

[27] A. B. R. Thomson, A. N. Barkun, D. Armstrong et al., "The prevalence of clinically significant endoscopic findings in primary care patients with uninvestigated dyspepsia: the Canadian Adult Dyspepsia Empiric Treatment-Prompt Endoscopy (CADETPE) study," Alimentary Pharmacology and Therapeutics, vol. 17, no. 12, pp. 1481-1491, 2003.

[28] S. J. Konturek, W. Bielański, M. Płonka et al., "Helicobacter pylori, non-steroidal anti-inflammatory drugs and smoking in risk pattern of gastroduodenal ulcers," Scandinavian Journal of Gastroenterology, vol. 38, no. 9, pp. 923-930, 2003.

[29] J. H. Kurata and A. N. Nogawa, "Meta-analysis of risk factors for peptic ulcer: nonsteroidal antiinflammatory drugs, Helicobacter pylori, and smoking," Journal of Clinical Gastroenterology, vol. 24, no. 1, pp. 2-17, 1997.

[30] R. J. F. Laheij, J. L. Severens, E. H. Van De Lisdonk, A. L. M. Verbeek, and J. B. M. J. Jansen, "Randomized controlled trial of omeprazole or endoscopy in patients with persistent dyspepsia: a cost-effectiveness analysis," Alimentary Pharmacology and Therapeutics, vol. 12, no. 12, pp. 1249-1256, 1998.

[31] S. Rosenstock, T. Jørgensen, O. Bonnevie, and L. Andersen, "Risk factors for peptic ulcer disease: a population based prospective cohort study comprising 2416 Danish adults," Gut, vol. 52, no. 2, pp. 186-193, 2003.

[32] J. S. Bolton and W. C. Conway, "Postgastrectomy syndromes," Surgical Clinics of North America, vol. 91, no. 5, pp. 1105-1122, 2011.

[33] ASGE Bariatric Endoscopy Task Force, S. Sullivan, N. Kumar et al., "ASGE position statement on endoscopic bariatric therapies in clinical practice," Gastrointestinal Endoscopy, vol. 82, no. 5, pp. 767-772, 2015.

[34] B. E. Schneider, L. Villegas, G. L. Blackburn et al., "Laparoscopic gastric bypass surgery: outcomes," Journal of Laparoendoscopic \& Advanced Surgical Techniques and Videoscopy, vol. 13, no. 4, pp. 247-255, 2003.

[35] C. A. Woodfield and M. S. Levine, "The postoperative stomach," European Journal of Radiology, vol. 53, no. 3, pp. 341-352, 2005.

[36] A. Quadri and N. Vakil, "Health-related anxiety and the effect of open-access endoscopy in US patients with dyspepsia," Alimentary Pharmacology and Therapeutics, vol. 17, no. 6, pp. 835-840, 2003.

[37] L. Rabeneck, K. Wristers, J. Souchek, and E. Ambriz, "Impact of upper endoscopy on satisfaction in patients with previously uninvestigated dyspepsia," Gastrointestinal Endoscopy, vol. 57, no. 3, pp. 295-299, 2003.

[38] Y. Zhao, D. Zou, R. Wang et al., "Dyspepsia and irritable bowel syndrome in China: a population-based endoscopy study of prevalence and impact," Alimentary Pharmacology and Therapeutics, vol. 32, no. 4, pp. 562-572, 2010.

[39] L. Petrarca, "Dyspepsia and celiac disease: prevalence, diagnostic tools and therapy," World Journal of Methodology, vol. 4, no. 3, pp. 189-196, 2014.

[40] R. Johnsen, B. Bernersen, B. Straume, O. H. Førde, L. Bostad, and P. G. Burhol, "Prevalences of endoscopic and histological findings in subjects with and without dyspepsia," British Medical Journal, vol. 302, no. 6779, pp. 749-752, 1991.

[41] G. N. J. Tytgat, "Role of endoscopy and biopsy in the work up of dyspepsia," Gut, vol. 50, no. 4, pp. iv13-iv16, 2002. 


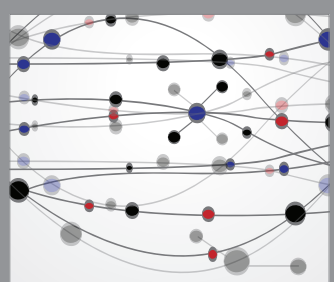

The Scientific World Journal
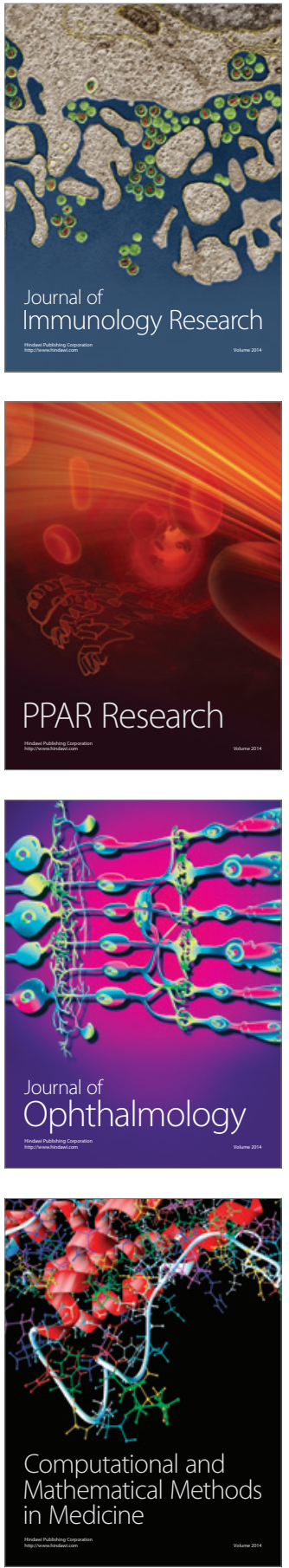

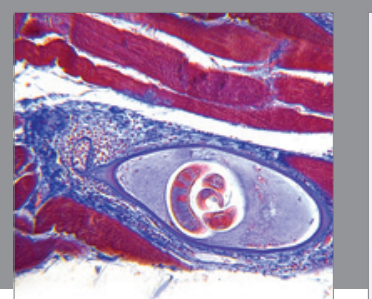

Gastroenterology Research and Practice
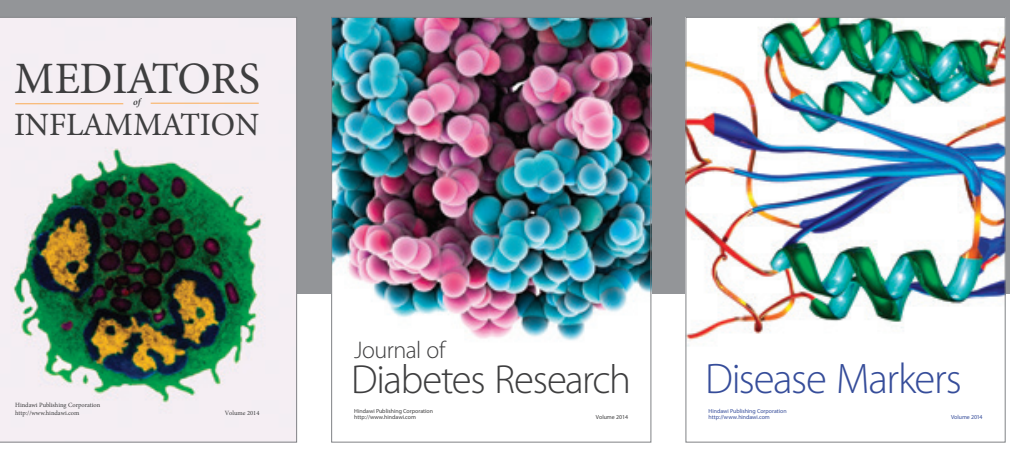

Disease Markers

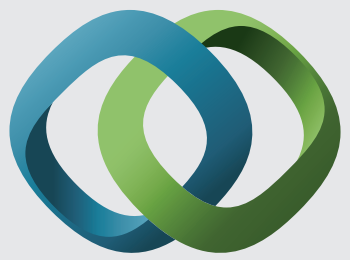

\section{Hindawi}

Submit your manuscripts at

https://www.hindawi.com
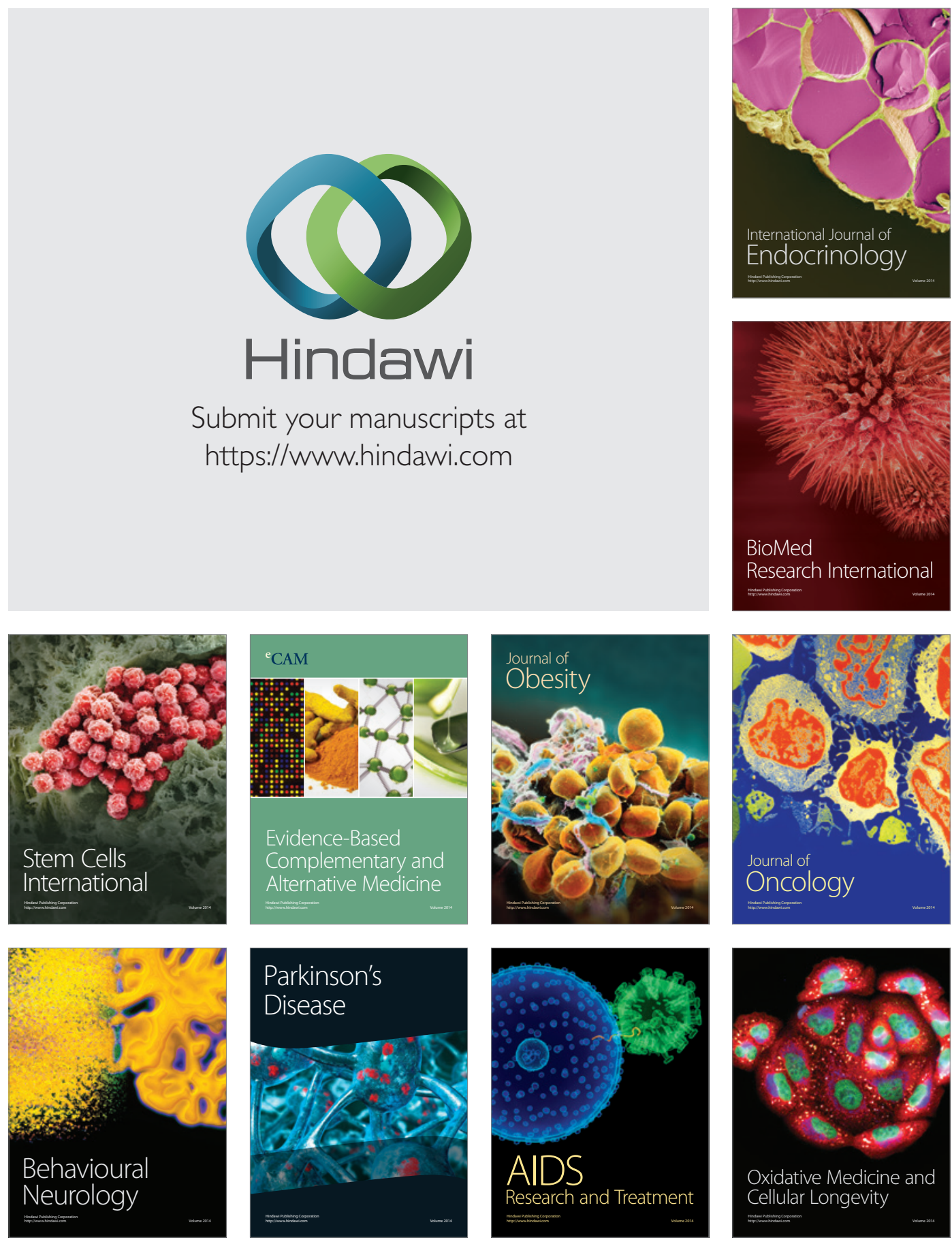